\title{
EFFECT OF BUTEYKO BREATHING TECHNIQUE ON QUALITY OF LIFE AMONG ASTHMATIC PATIENTS AT MANSOURA UNIVERSITY HOSPITAL ${ }^{1}$ Fatma Mohmmed Ahmed Abouelala, ${ }^{2}$ Wafaa Ismail Sherif, ${ }^{3}$ Karima Fouad Elshamy, ${ }^{4}$ Nesrien Mohmed Shalabi \\ 1Assistance Lecturer of Medical Surgical Nursing, Faculty of Nursing, Damnhour University. \\ 2 Professor of Medical Surgical Nursing department, Faculty of Nursing, Mansoura University. 3Assistant professor of Medical Surgical Nursing, Faculty of Nursing, Mansoura University. 4Assistant professor of Chest Diseases, Faculty of Medicine, Mansoura University.
}

\begin{abstract}
:
Bronchial asthma (BA) is one of the most common chronic lung diseases, in both the developed and developing countries. There has been a sharp increase in the global prevalence, morbidity, mortality, and financial burden associated with asthma. Buteyko Breathing Technique (BBT) is the most effective a natural drug-free alternative therapy for asthma management. BBT showed a significant improvement in quality of life (QoL) and asthma control. This study aims to assess the effect of BBT on quality of life in patients with bronchial asthma. Subjects \& Methods: Quasi-experimental design was conducted. A purposive sample of 90 asthmatic patients was included from out-patients of chest diseases department, Mansoura university Hospital over a period of 12 months. Data were collected using one tool "Patients' Interview Assessment Sheet" which include 2 parts 1) Socio demographic data, 2) Quality of Life Questionnaire (pre-test, and post-test). Results: revealed that, improvement of QoL total score $49.2 \pm 8.4$ to reach $60.4 \pm 12.9$ post implementing BBT compared to $51.5 \pm 8.6$ to reach $53.5 \pm 9.1$ of the control group after three months. Conclusion: The intervention group shows significant improvement of total quality of life scores Recommendations: further studies to investigate the impact of BBT on patients of bronchial asthma on long run studies.
\end{abstract}

Key words: Bronchial Asthma, Quality of Life, Buteyko Breathing Technique

\section{Introduction:}

Asthma is a global health problem not limited to certain age but distressing all people at any age group. The incidence rate of asthma increased rapidly over the last century, not only in the developing country but also in developed one. Current estimates suggest that asthma affects 300 million people world-wide and an additional 100 million persons will be diagnosed by 2025 . It has bad effect on different life activities where it leads to days lost from school or work, unscheduled health-care visits, hospital admissions and disruption to daily life activities $^{(1)}$.

Asthma is more serious in countries with limited resources and lower public awareness. In Egypt and Middle East Countries, asthma became a real challenge and a major public health problem ${ }^{(2)}$. The prevalence of asthma in Egypt still underestimated. Furthermore, the world health survey was implemented by WHO (2002-2004) with the participation of 70 countries to estimate the prevalence of bronchial asthma in adult population in different countries, Egypt did not participate in this survey ${ }^{(3)}$.

Asthma is a chronic inflammatory disease of the airways that causes airway hyper-responsiveness, mucosal edema, and mucus production. This inflammation ultimately leads to recurrent episodes of asthma symptoms, cough, chest tightness, 
wheezing, and dyspnea ${ }^{(4)}$. During acute episode airflow obstruction reverses either spontaneously or with treatment. Although most episodes are relatively brief, some individual with asthma may experience longer episodes with some degree of airway impairment daily. In uncommon cases, an acute episode of asthma is so severe that may result in respiratory failure and death ${ }^{(5)}$.

Despite increased knowledge regarding the pathology of asthma and the development of improved medications and management plans, the death rate from the disease continues to rise ${ }^{(4)}$.

As asthma is a breathing disorder of the lung, poor breathing habits can aggravate the symptoms of asthma, breathing retraining include manipulation of the breathing pattern, deep breathing, and relaxation technique showed improvement in quality of life and asthma control in asthmatic patients ${ }^{(5-6)}$.

The Buteyko breathing technique (BBT) was developed by Professor Buteyko; he stated that many chronic diseases, including asthma could be scientifically explained as being a consequence of hyperventilation. The aim of Buteyko breathing retraining is to contrary chronic hyperventilation and return to a healthy breathing pattern ${ }^{(7)}$.

Buteyko breathing technique is a complementary technique used to control over breathing, which can improve asthma symptoms, quality of life and reduce bronchodilator used in patients with asthma ${ }^{(8-9)}$. BBT are now cited in several guidelines for asthma management as The British Guideline on the Management of Asthma 2016, states that the Buteyko method "may be considered to help patients control the symptoms of asthma, improve asthma quality of life and give it grade $1^{++}$with a very low risk of bias" (10).

\section{Aim of the study}

The study aims to assess the impact of BBT on quality of life in patients with bronchial asthma.

\section{Research Hypothesis}

Patients who practice Buteyko Breathing Technique (BBT) (Buteyko group) will exhibit higher score of quality of life than control group.

\section{Subjects and methods \\ Research design}

Quasi-experimental design was conducted.

\section{Research Setting}

This study was conducted in the outpatient clinic of Chest Diseases Department, Mansoura University Hospital.

\section{Subjects}

A purposive sample of 90 patients was recruited. The subjects of the study were diagnosed as bronchial asthma, aged 20 to 60 years old, cooperative, willing to participate in the study, available for telephone contact, and not participated to other alternative therapy for BA management.

Patients with any history of other chronic diseases such chronic bronchitis, emphysema, hypertension, heart diseases, epilepsy, kidney diseases, hepatic disorder, diabetes and mentally retarded, psychological disorder and pregnant women were excluded from the study.

All subjects were randomized into control group $(\mathrm{N}=45)$ who received the routine medical treatment only and the Buteyko group $(\mathrm{N}=45)$ who received the routine medical treatment in addition to BBT.

Tools for Data Collection

One tool was used by the researcher for the purpose of data collection 
Tool I "Patients' Interview Assessment Sheet" this consisted of two parts.

Part 1: "Patients socio demographic data" this part was developed by the researcher and composed of seven items that include sex, age, weight, marital status, level of education, and job status.

Part 2 "Mini asthma quality of life questionnaire" it was adopted from (Juniper et al., 1999) (11), the questionnaire was containing 15 items of likert scale. It was tested four domains which include symptoms frequency (5 items), activity limitation (4 items), emotional function (3 items) and environmental stimuli ( 3 items).

The total score was recorded as the average of the scores in the 15 questions. The answers to each question are scored one to seven $(1=$ maximum impairment and $7=$ no impairment). The mean score per domain then total score calculated. An overall score of quality of life rated as: $\geq$ $75 \%$ indicated high quality of life, $50 \%$ to $<75 \%$ indicated moderate quality of life, and $<50 \%$ indicated Low quality of life.

\section{Methods}

- Permission to conduct the study was obtained from the responsible authorities of the Faculty of Nursing, Mansoura University, and the Chest Diseases Department of Mansoura University Hospital.

- A representative sample size was calculated using $G$ power software program version 3.1.

- Validity of the tool, it was submitted to a jury composed of six experts from faculty of nursing and faculty of medicine, Mansoura University. They were asked to judge completeness, accuracy, and relevance of the content of the tool and the necessary modifications were done.

- Reliability of tools, it was tested for its internal consistency using Cronbach's Alpha test, the coefficient value was
0.678

- The Buteyko Breathing Technique booklet was developed and translated into simple Arabic language by the researcher based on review of the recent related literature and supplied by clear and descriptive pictures.

- Pilot study was conducted to test the clarity and applicability of the tool on 10 patients these patients were not included in the study sample.

\section{Data collection phase}

- According to the previously mentioned study criteria, the patients were randomly assigned into control group and Buteyko group. The first 45 asthmatic patients were interviewed in outpatient clinic considered as the control group. The next 45 asthmatic patients constituted the Buteyko group.

- Data was collected by the researcher, over a period of one year from 1/9/2014 to $31 / 8 / 2015$ on Saturday and Monday of each week from 9 am to $1 \mathrm{pm}$.

The data was collected through three phases:

1. Assessment phase

- Patients' reports revised by the researcher to confirm the diagnosis of bronchial asthma.

- Prepare the environment as it was calm, free from external stimuli as possible, supplemented with chair with back support to promote patients' relax, stop watch, mouth tap, and pen.

- The data was collected from the patients using study tool (pre-test) via face to face interview; it was taken about 20-30 minutes.

2. Implementation of Buteyko Breathing Technique Phase: The content of the BBT included an educational and training component guided with; Courtney (2014), Lewis, et al., (2014), Buteyko Breathing Association (2010), Lingard (2008), and McKeown (2009). ${ }^{(12-16)}$ 
i. Educational components Educational components were including behavior and lifestyle modification as avoidance of asthma triggers, stop smoking, nutritional modifications, avoid of colds and flu, physical activity. Educational component was covered in about 20 minutes in one session.

\section{ii. Training components}

Each training session took about 3060 minutes. Training was conducted in 4 sessions, one session every week for 4 weeks; patient follow up was achieved through patients' interview in outpatient clinic or by telephone contact. The patients were advised to practice BBT three times per day, generally before eating or two hours after eating (three repetitions for each one).

\section{A. First training session (first week)}

On the first week patients were learned new skills as, nose breathing, nose clearing exercise, control pause, relaxed and diaphragmatic breathing, and how to stop cough naturally.

\section{B. Second training session (second week)}

At the beginning of second week, the patients were learned how to practice reduced breathing and extended pause.

\section{Third and fourth session (third and fourth week)}

It is important to continue to perform the BBT in the third and fourth week, where the objective to continue to exercise in that period to learn how to reduce the number of breaths to lower than normal, which called very reduced breathing.

\section{Evaluation phase}

- Reassessment of the studied subjects using study tools after three months (posttest).

- Comparison between Buteyko and control groups finding were done to evaluate the impact of BBT on level of quality of life.

\section{Ethical consideration}

- Ethical approval will be obtained from the Research Ethics Committee of the Faculty of Nursing, Mansoura University.

-Consent and confidentiality was considered by the researcher through introduced herself to the patients, explained the purpose and benefits of the study.

- An oral consent was obtained from the subjects of the study.

- Patients have the right to withdraw from the study at any point of time.

\section{Statistical analysis}

- After data were collected it was revised, coded and fed to statistical software IBM SPSS version 20. The given graphs were constructed using Microsoft excel software. All statistical analysis was done using two tailed tests and alpha error of 0.05 . $\mathrm{P}$ value less than or equal to 0.05 was considered to be statistically significant. 
EFFECT OF BUTEYKO BREATHING TECHNIQUE ON etc...

\begin{tabular}{|c|c|c|c|c|c|}
\hline \multirow{2}{*}{$\begin{array}{c}\text { Bio-Socio- } \\
\text { demographic } \\
\text { Characteristics } \\
\end{array}$} & \multicolumn{2}{|c|}{$\begin{array}{l}\text { Buteyko Group } \\
\text { (45) }\end{array}$} & \multicolumn{2}{|c|}{ Control Group (45) } & \multirow[t]{2}{*}{ P Value } \\
\hline & NO & $\%$ & $\mathrm{NO}$ & $\%$ & \\
\hline \multicolumn{6}{|l|}{ Gender } \\
\hline Male & 18 & $\begin{array}{c}40.0 \\
\%\end{array}$ & 22 & $48.9 \%$ & \multirow[t]{2}{*}{$0.396 !$} \\
\hline Female & 27 & $60.0 \%$ & 23 & $51.1 \%$ & \\
\hline \multicolumn{6}{|l|}{ Age (years) } \\
\hline $20-$ & 17 & $\begin{array}{c}37.8 \\
\%\end{array}$ & 11 & $24.4 \%$ & \multirow[t]{4}{*}{$0.586^{\wedge}$} \\
\hline $30-$ & 12 & $\begin{array}{c}26.7 \\
\%\end{array}$ & 13 & $28.9 \%$ & \\
\hline $40-$ & 11 & $\begin{array}{c}24.4 \\
\%\end{array}$ & 14 & $31.1 \%$ & \\
\hline $50-60$ & 5 & $\begin{array}{c}11.1 \\
\%\end{array}$ & 7 & $15.6 \%$ & \\
\hline Mean \pm SD & \multicolumn{2}{|c|}{$34.5 \pm 10.8$} & \multicolumn{2}{|c|}{$37.6 \pm 10.9$} & \\
\hline \multicolumn{6}{|l|}{ BMI } \\
\hline $\begin{array}{l}\text { Normal weight (18.5- } \\
\text { 24.9) }\end{array}$ & 10 & $\begin{array}{c}22.2 \\
\%\end{array}$ & 6 & $13.3 \%$ & \multirow[t]{3}{*}{$0.543^{\wedge}$} \\
\hline Overweight (24-29.9) & 15 & $\begin{array}{c}33.3 \\
\%\end{array}$ & 17 & $37.8 \%$ & \\
\hline Obese (30 or more) & 20 & $\begin{array}{c}44.4 \\
\%\end{array}$ & 22 & $48.9 \%$ & \\
\hline \multicolumn{6}{|l|}{ Marital status } \\
\hline Married & 29 & $\begin{array}{c}64.4 \\
\%\end{array}$ & 28 & $62.2 \%$ & \multirow[t]{2}{*}{$0.827 !$} \\
\hline Unmarried & 16 & $\begin{array}{c}35.6 \\
\%\end{array}$ & 17 & $37.8 \%$ & \\
\hline \multicolumn{6}{|l|}{ Level of education } \\
\hline Illiterate & 15 & $\begin{array}{c}33.3 \\
\%\end{array}$ & 18 & $40.0 \%$ & \multirow{4}{*}{$0.465^{\wedge}$} \\
\hline Primary & 7 & $\begin{array}{c}15.6 \\
\%\end{array}$ & 5 & $11.1 \%$ & \\
\hline Secondary & 18 & $\begin{array}{c}40.0 \\
\%\end{array}$ & 13 & $28.9 \%$ & \\
\hline Bachelor & 5 & $\begin{array}{c}11.1 \\
\%\end{array}$ & 9 & $20.0 \%$ & \\
\hline \multicolumn{6}{|l|}{ Job status } \\
\hline Unemployed & 29 & $\begin{array}{c}64.4 \\
\%\end{array}$ & 26 & $57.8 \%$ & \multirow[t]{3}{*}{$0.517^{\wedge}$} \\
\hline Manual worker & 16 & $\begin{array}{c}35.6 \\
\%\end{array}$ & 19 & $42.2 \%$ & \\
\hline Smoking habit & & & & & \\
\hline
\end{tabular}


Fatma Mohmmed Ahmed Abouelala et. al.

\begin{tabular}{|l|c|c|c|c|c|}
\hline Smoker & 2 & $4.4 \%$ & 1 & $2.2 \%$ & \multirow{2}{*}{$0.283^{\wedge}$} \\
\cline { 1 - 4 } non smoker & 33 & $\begin{array}{c}73.3 \\
\%\end{array}$ & 30 & $66.7 \%$ & \\
\cline { 1 - 4 } passive smoker & 7 & $\begin{array}{c}15.6 \\
\%\end{array}$ & 5 & $11.1 \%$ & \\
\hline Quitter & 3 & $6.7 \%$ & 9 & $20.0 \%$ & \\
\hline
\end{tabular}

$\wedge$ : P value based on Mont Carlo exact probability

! Fisher exact probability

Table (1): A group of 90 patients were enrolled in the study. Regarding to gender the results revealed that more than half of study groups were females; it was distributed as $60.0 \%$ in Buteyko group and $51.1 \%$ in the control group. The age of the studied sample ranged from 20 to 60 years, more than one third $37.8 \%$ of patients in the Buteyko group were in the age group of 20 to less than 30 compared to about one third $31.1 \%$ of the control group in the age group 40 to less than 50 years, while the least percentage of patients in two groups were in the age group of 50 to less than 60 years. The mean age was $34.5 \pm$ and $37.6 \pm 10.9$ for the Buteyko and control groups respectively. 
As regards BMI, the highest percentage $44.4 \%$ of Buteyko group and $48.9 \%$ of control group were obese, while the least percentage of patients in two groups was normal weight $22.2 \%$ and $13.3 \%$ respectively. In reference to marital status, $64.4 \%$ of Buteyko group and $62.2 \%$ of control group were married. Concerning level of education more than one third 40.0 $\%$ Buteyko group had secondary education, comparing with the same percent $40.0 \%$ of control group was in favor of the illiteracy. As regarding to job, the highest percentage $64.4 \%$ of Buteyko group and $57.8 \%$ of control group were unemployed.

Regarding to smoking habit, the majority of patients were non smoker distributed as $73.3 \%$ in the Buteyko group and $66.7 \%$ in the control group, and in the opposite direction the minority of patients in Buteyko and control group was smokers representing $4.4 \%$ and $2.2 \%$ respectively.

Table (2): Comparison between Control and Buteyko Groups in Relation to Quality of Life Domains Pre and Post Intervention (No = 90).

\begin{tabular}{|c|c|c|c|c|c|c|c|c|c|c|}
\hline \multirow{3}{*}{$\begin{array}{c}\text { Quality of Life } \\
\text { Domains }\end{array}$} & \multicolumn{4}{|c|}{ Buteyko Group (45) } & \multirow{3}{*}{$\begin{array}{c}P \\
\text { Value }\end{array}$} & \multicolumn{4}{|c|}{ Control Group (45) } & \multirow{3}{*}{$\begin{array}{c}\mathbf{P} \\
\text { Value }\end{array}$} \\
\hline & \multicolumn{2}{|c|}{ Pre } & \multicolumn{2}{|c|}{ Post } & & \multicolumn{2}{|c|}{ Pre } & \multicolumn{2}{|c|}{ Post } & \\
\hline & No & $\%$ & No & $\%$ & & No & $\%$ & No & $\%$ & \\
\hline $\begin{array}{l}\text { Symptoms } \\
\text { frequency }\end{array}$ & & & & & & & & & & \\
\hline Low & 30 & $66.7 \%$ & 10 & $22.2 \%$ & $0.001 *$ & 32 & $71.1 \%$ & 33 & $73.3 \%$ & 0.814 \\
\hline Moderate & 15 & $33.3 \%$ & 23 & $51.1 \%$ & & 13 & $28.9 \%$ & 12 & $26.7 \%$ & \\
\hline High & 0 & $0.0 \%$ & 12 & $26.7 \%$ & & 0 & $0.0 \%$ & 0 & $0.0 \%$ & \\
\hline $\begin{array}{l}\text { Environmental } \\
\text { stimuli }\end{array}$ & & & & & & & & & & \\
\hline Low & 42 & $93.3 \%$ & 42 & $93.3 \%$ & 1.000 & 41 & $91.1 \%$ & 42 & $93.3 \%$ & 0.899 \\
\hline Moderate & 3 & $6.7 \%$ & 3 & $6.7 \%$ & & 3 & $6.7 \%$ & 2 & $4.4 \%$ & \\
\hline High & 0 & $0.0 \%$ & 0 & $0.0 \%$ & & 1 & $2.2 \%$ & 1 & $2.2 \%$ & \\
\hline $\begin{array}{l}\text { Emotional } \\
\text { status }\end{array}$ & & & & & & & & & & \\
\hline Low & 26 & $57.8 \%$ & 15 & $33.3 \%$ & $0.048 *$ & 19 & $42.2 \%$ & 20 & $44.4 \%$ & 0.968 \\
\hline Moderate & 11 & $24.4 \%$ & 14 & $31.1 \%$ & & 13 & $28.9 \%$ & 13 & $28.9 \%$ & \\
\hline High & 8 & $17.8 \%$ & 16 & $35.6 \%$ & & 13 & $28.9 \%$ & 12 & $26.7 \%$ & \\
\hline $\begin{array}{l}\text { Activity } \\
\text { limitation }\end{array}$ & & & & & & & & & & \\
\hline Low & 5 & $11.1 \%$ & 3 & $6.7 \%$ & $0.016^{*}$ & 4 & $8.9 \%$ & 3 & $6.7 \%$ & 0.882 \\
\hline Moderate & 31 & $68.9 \%$ & 20 & $44.4 \%$ & & 26 & $57.8 \%$ & 28 & $62.2 \%$ & \\
\hline High & 9 & $20.0 \%$ & 22 & $48.9 \%$ & & 15 & $33.3 \%$ & 14 & $31.1 \%$ & \\
\hline
\end{tabular}

* Statistically significant ( $\mathrm{P}$ value $\leq 0.05$ )

Low Score: $<50 \%$

Moderate Score: $50 \%-<75 \% \quad$ High Score: $\geq 75 \%$

Table (2): For Buteyko group, there was statistical significant difference in the distribution of the following quality of life domains post implementing BBT; symptoms frequency, emotional status and activity limitation $\mathrm{p}$ value at $0.001^{*}$, $0.048^{*}, 0.016 *$ respectively, but did not show any significant difference toward environmental stimuli $\mathrm{p}$ value at 1.000 .

As regarding to control group this table did not show any significant difference toward all quality of Life domains that namely symptoms frequency, environmental stimuli, emotional status 
and activity limitation during study phases $\mathrm{p}$ value at $0.814,0.899,0.968,0,882$

respectively.

Table (3): Distribution of Total Percentage of Overall Quality of Life Scores among Studied Groups pre and post intervention $\left(\mathrm{No}_{\mathrm{O}}=90\right)$.

\begin{tabular}{|c|c|c|c|c|c|c|c|c|c|c|}
\hline \multirow{3}{*}{$\begin{array}{c}\text { Overall } \\
\text { QOL }\end{array}$} & \multicolumn{4}{|c|}{ Buteyko Group A (45) } & \multirow{3}{*}{$\begin{array}{c}P \\
\text { Value }\end{array}$} & \multicolumn{4}{|c|}{ Control Group (45) } & \multirow{3}{*}{$\begin{array}{c}\mathbf{P} \\
\text { Value }\end{array}$} \\
\hline & \multicolumn{2}{|c|}{ Pre } & \multicolumn{2}{|c|}{ Post } & & \multicolumn{2}{|c|}{ Pre } & \multicolumn{2}{|c|}{ Post } & \\
\hline & No & $\%$ & No & $\%$ & & No & $\%$ & No & $\%$ & \\
\hline Low & 29 & $64.4 \%$ & 16 & $35.6 \%$ & & 27 & $60.0 \%$ & 25 & $55.6 \%$ & \\
\hline Moderate & 16 & $35.6 \%$ & 25 & $55.6 \%$ & $0.008 *$ & 18 & $40.0 \%$ & 19 & $42.2 \%$ & 0.576 \\
\hline High & 0 & $0.0 \%$ & 4 & $8.9 \%$ & & 0 & $0.0 \%$ & 1 & $2.2 \%$ & \\
\hline Range & \multicolumn{2}{|c|}{$28-67$} & \multirow{2}{*}{\multicolumn{2}{|c|}{$\begin{array}{c}30-87 \\
60.4 \pm 12.9\end{array}$}} & & \multicolumn{2}{|c|}{$28-74$} & \multicolumn{2}{|c|}{$36-80$} & \\
\hline Mean \pm SD & \multicolumn{2}{|c|}{$49.2 \pm 8.4$} & & & & \multicolumn{2}{|c|}{$51.5 \pm 8.6$} & \multicolumn{2}{|c|}{$53.5 \pm 9.1$} & \\
\hline
\end{tabular}

* Statistically significant (P value $\leq 0.05$ )

Low Score: $<50 \% \quad$ Moderate Score: $50 \%-<75 \%$ High Score: $\geq 75 \%$

Table (3): This table reveals that statistically significant difference in distribution of the total score levels of quality of life among the study group $\mathrm{p}$ value at $0.008^{*}$, with improvement in mean and stander deviation from

$49.2 \pm 8.4$ to reach $60.4 \pm 12.9$ post implementing BBT. Moreover, there was slight improvement in mean of the control group from $51.5 \pm 8.6$ to reach $53.5 \pm 9.1$ after three months, but this improvement did not differ significantly $\mathrm{p}$ value at 0.576 . Obviously, this table shows that the Buteyko group got higher percentage of the high level of quality of life score than control group $8.9 \%$ versus $2.2 \%$ respectively

\section{Discussion:}

Socio-demographic data of the present study showed that, more than half of studied groups were females this finding agree with Papadakis \& Mcphee (2014) \& Niitsuma (2004), who stated that asthma a slightly more common in female adult ${ }^{(17-18)}$ and come in the same line with Zein \& Erzurum (2015), who stated that asthma becomes more prevalent and severe in women after puberty, this may be attributed to a role for sex hormones in asthma genesis ${ }^{(19)}$.

Regarding to age, the studied sample mean age was $34.5 \pm 10.8$ year and $37.6 \pm$ year for the Buteyko and control groups respectively. This finding come in agreement with Opat et al., (2000), who found that the mean age was $(31.6 \pm 9.5)$ for Buteyko group and 32.7 \pm 11.7 for placebo group ${ }^{(20)}$.

On the other hand, the mean age of the studied sample seems to be less than other study carried by Cowie et al., (2008), who founded that the mean age was $47 \pm 12.5$ for Buteyko group and $48 \pm 12.5$ for control group. As well as McHugh et al., (2003), in their study who stated that mean age was 48.8 year for BBT group and 44.0 year for control group. This difference in the mean age and current study may be due to this two studies included age group more than 60 years which excluded in current study ${ }^{(21-22)}$.

As regards BMI, results of the present study denoted more than two fifth of Buteyko group and less than half of control group were obese, this finding supported by Baffi et al., (2015) ${ }^{(23)}$ who stated that obesity is associated with increased asthma morbidity rates with the increase in prevalence rates. In the same 
line Manion (2013), concluded that obesity is a risk factor for asthma in multiple demographic groups ${ }^{(24)}$. This finding was supported by Thomas \& Bruton (2014), who reported that median body mass index was 27.7 and 25.7 which reflect over weight for both breathing training group and control group respectively in their study which conducting in Leicester, UK ${ }^{(8)}$.

On the other hand, this finding is in contrary with Kalpana (2010), in his study about effect of pranayama on chronic asthma which carried in India, he found that their all studied subjects have normal body mass index 22.7, 22.6, 24.5 for pranayama group, respiratory physiotherapy, and control group respectively ${ }^{(25)}$.

Regarding educational level, the finding of the present study revealed that two fifth of the study group was has secondary level of education, while the same percent $40.0 \%$ of control group was illiterate. This result may be due to the most of the patients attaining to the outpatient clinic came from rural areas with low socio-economic status and low educational level.

This finding was in consistence with a study conducting in Egypt and found that the majority of the studied sample was illiterate (26). On the other side Uchmanowicz et al., (2016), reported that the highest percentage of studied subject have high school of education ${ }^{(27)}$.

In relation to job status, the highest percentage less than two thirds of Buteyko group and more than half of control group were unemployed, this may be related to more than half of study groups were females besides the majority of them are house wives. This finding in agreement with Taha \& Ali (2011), who reported that more than two thirds $(69.0 \%)$ of studied subject were unemployed ${ }^{(26)}$.

Regarding to smoking habit, nearly to three quarters of study group were non- smoker and two thirds in the control group. This result seems to be logic due to smoking consider one of asthma triggers. In the same line a study done by Prasanna et al., (2015), the study subjects were all nonsmokers similar to the current study in which the majority of study subjects were also non smokers ${ }^{(28)}$. Also Cowie et al., (2008), stated that about three quarters for both Buteyko and control group were nonsmoker ${ }^{(21)}$. In the opposite direction Refaat \& Aref (2014), reported that about one quarter (25.5) of studied sample were smoker (29).

In reference to assessment of quality of life among studied subjects the present study illustrated that significant improvement in all quality of life domains except in environmental stimuli among Buteyko group after implementing BBT. The control group did not show any significant difference toward all quality of life domains that namely symptoms frequency, environmental stimuli, emotional status and activity limitation after three months from conducting the study.

There was moderate improvement in total mean score from $49.2 \pm 8.4$ to reach $60.4 \pm 12.9$ post implementing BBT. Furthermore, there was little improvement in total mean of the control group from $51.5 \pm 8.6$ to reach $53.5 \pm 9.1$ after three months, this improvement did not differ significantly.

Results of the present study indicate that the quality of life of people with asthma before implementing BBT is relatively low. In the same line OA Oni et al., (2014), stated that quality of life for patients with asthma was relatively low (30). Also in an article published by Uchmanowicz et al., (2016), in Poland it was shown that asthma has clearly negative effect on quality of life especially causes restrictions on the activities of patients with bronchial asthma ${ }^{(27) .}$ 
This finding is in agreement with Villareal et al., (2014), in their study which conducted in Manila City, Philippines who stated that the Buteyko group showed a significant improvement of their quality of life scores postintroduction of BBT $(\mathrm{t}=-3.846, \mathrm{p}=0.006)$. These findings reveal that Buteyko method can improve the quality of life of asthmatic patients ${ }^{(31)}$.

These results were highly supported with British Clinical Guideline (2014), which noted that practice BBT for adult with asthma could improve asthma symptoms and quality of life ${ }^{(32)}$. This finding was congruent with Bowler et al., (1998), they founded that $54 \%$ improvement in total quality of life score at 6 weeks ${ }^{(33)}$.

On the opposite direction, this finding is in disagreement with Slader et al., (2006), who concluded that quality of life scores unaffected for BBT group and breathing exercises groups ${ }^{(34)}$.

\section{Conclusion}

Based on the findings of the current study, it can be concluded that, the Buteyko group shows significant improvement of total QoL mean scores in Buteyko group after implementing BBT.

\section{Recommendations:}

According to results of this study, the following suggestions are recommended:

1) Early conduction of BBT for asthmatic patient with inclusion criteria that encourages selfmanagement and reduces the cost of medication.

2) The developed BBT booklet should be distributed to all chest departments of Dakahlia governorate.

3) Further studies to investigate the effect of BBT on patients with bronchial asthma regarding; quality of life on long run studies and long period of follow-up with large sample.

\section{References}

1. Walker B, Colledge N, Ralston S \& Penman I (2014): Davidson's Principle \& Practice of Medicine 22nd ed., Elsevier Limited, China, pp 665-671.

2. Abdulrahman, H., Hadi, U., Tarraf, H., Gharagozlou, M., Kamel, M., Soliman, A., \& Abdelmotal, A. (2012): Nasal allergies in the Middle Eastern population: results from the Allergies in Middle East Survey. American journal of rhinology \& allergy, 26(6), S3-S23.

3. WHO (2015): Fact Sheet No 206: "Asthma" available at http://www.who.int/healthinfo/survey/e n/. Accessed on Jun, 12, 2016, 10PM.

4. Hinkle, J., \& Cheever, K., (2014): Brunner \& Suddarth's Textbook of Medical-Surgical Nursing 13th ed. Lippincott Williams \& Wilkins. Pp 1369-1376.

5. Malone L, Fletcher K, \& Plank L (2014): Advanced Practice Nursing in the Care of Older Adults. 10th ed. Philadelphia, F.A Davis Company, pp. 196.

6. Holloway E, West R (2007): Integrated breathing and relaxation training, the Papworth method for adults with asthma in primary care: A randomized trial. Thorax; 62:1033-4.

7. Thomas, M., McKinley, R., Freeman, E., Foy, P., Prodger, P., \& Price, D. (2003): Breathing retraining for dysfunctional breathing in asthma: a randomised controlled trial. Thorax, 58(2), 110-115.

8. Thomas, M., \& Bruton, A. (2014): Breathing exercises for asthma. Breathe, 10(4), 312-322.

9. Ruth, A., (2014): The Buteyko breathing technique in effective asthma management. Nursing in General Practice, 7(2), 14-16. 
EFFECT OF BUTEYKO BREATHING TECHNIQUE ON etc...

10. British Thoracic Society \& Scottish Intercollegiate Guidelines Network (2016): British Guideline on the Management of Asthma; Available at www.sign.ac.uk/pdf/sign101.pdf p. 61. Accessed on June, 25,2016, 11 AM.

11. Juniper E, Guyatt E, Cox F, Ferrie P, King D, (1999): Development and validation of the mini asthma quality of life questionnaire. European Respiratory Journal, 14(1), 32-38.

12. Courtney, R., (2014): 'Buteyko Breathing Method', Chapter 8.2 of the book titled 'Recognizing and Treating Breathing Disorders', Churchill Livingstone Elsevier pp 241-247.

13. Lewis, S., Driksen, S., Heitkempet, M., \& Bucher, L., (2014): Medical Surgical Nursing Assessment and Management of Clinical Problem. 9th ed, Canada, Mosby, P571.

14. Buteyko Breathing Association (2010): Buteyko Practice Diary and Quick Reference Guide Available at www.buteykobreathing.org.

Accessed in 15 January 2014.

15. Lingard, M., (2008): The Buteyko Guide to Better Asthma Management. Totahealth Matters, UK. Pp 8-12, available at https://books.google.com/books, accessed on May11/2014.

16. Mckeown, P., (2009): close your mouth Buteyko breathing clinic selfhelp Buteyko Books. Buteyko Books Loughwell, Moycullen, Co.Galway available at: www.ButeykoClinic.com. Accessed on March 20/2014

17. Papadakis, M \& Mcphee, S (2014): Current medical diagnosis and treatment, 53rd ed., New York: McGraw-Hill Medical, pp 235-46.

18. Niitsuma T., Tsuji M., Nukaga A., Izawa M., Okita N., Maruoka, A.,
Oguchi S., Morita Y., Matsumura M.,

Tsuyuguchi T., \& Hayashi, (2004): Thirty cases of bronchial asthma associated with exposure to pet hamsters. Journal of Investigational Allergology and Clinical Immunology, 14, 221-24.

19. Zein J., \& Erzurum S., (2015): Asthma is Different in Women Curr Allergy Asthma Rep. 15(6):28. Accessed on May,2016, 9AM.

20. Opat A, Cohen M, Bailey M, \& Abramson M (2000): A clinical trial of the Buteyko Breathing Technique in asthma as taught by a video. Journal of Asthma, 37(7), 557-64.

21. Cowie L, Conley P, Underwood F, et al. A randomised controlled trial of the Buteyko technique as an adjunct to conventional management of asthma.Respir Med 2008; 102: 726723.

22. McHugh, P., Aitcheson, F., Duncan, B., \& Houghton, F., (2003): Buteyko Breathing Technique for asthma: an effective intervention. The New Zealand Medical Journal, 116(1187).

23. Baffi, C., Winnica, D., \& Holguin, F., (2015): Asthma and obesity: mechanisms and clinical implication Asthma Research and Practice, 1(1),

24. Manion A. (2013): Asthma and obesity: the dose effect. Nurs Clin North Am, 48(1), 151-158. Available at_ https://www.ncbi.nlm.nih.gov/pubme $\mathrm{d} / 23465448$, accessed on 7 June 2015.

25. Kalpana, A., (2010): effect of pranayama on chronic bronchial asthma. Thesis for the partial fulfillment of the requirement of the doctorate degree faculty of medicine, Manipal University, India, pp. 126151, available at http://hdl.handle.net/10603/2339. Accessed on April 2016. 
26. Taha, M., \& Ali, Z., (2011): Effect of Therapeutic Guidelines for Bronchial Asthma on Adult Patients' Knowledge, Practice, Compliance, and Disease Severity Life Science Journal;8(3) available at http://www.lifesciencesite.com. Accessed on 14 March 2015.

27. Uchmanowicz B., Panaszek B., Uchmanowicz I., and Rosińczuk J., (2016): Sociodemographic factors affecting the quality of life of patients with asthma, Patient Prefer Adherence; 10: 345-354. Accessed May, 10, 2017, 11 PM.

28. Prasanna K, Sowmiya K, Dhileeban C. Effect of Buteyko breathing exercise in newly diagnosed asthmatic

patients. Int $\mathrm{J}$ Med Public Health 2015;5:77-81.

29. Refaat S, Aref H. Acute asthma in emergency department, prevalence of respiratory and non-respiratory symptoms. Egypt J Chest Dis Tuberc. 2014;63(4):776-771.

30. Oni O, Erhabor G, Oluboyo P (2014): Does Health Related Quality of life in asthma patients correlate with the clinical indices? south African family practice 2014; 56: 2,134-138.
31. Villareal M, Villazor B, Villegas A, Visaya $\mathrm{P}$, Vista $\mathrm{M}$, Tan $\mathrm{C}$, \& Florendo C., (2014): Effect of Buteyko Method on Asthma Control and Quality of Life of Filipino Adults with Bronchial Asthma. The Journal of MacroTrends in Health and Medicine. 2(1).

32. British guideline on the management of asthma management. (2014): Thorax Practice guideline. 69 Suppl 1: 56. Accessed on Febryary, 8, 2016. 10 AM.

33. Bowler S, Green A, Mitchell C. Buteyko breathing techniques in asthma: a blinded randomised controlled trial. Medical Journal of Australia 1998; 169: 575-78.

34. Slader, C., Redde, H., Spencer, L., Belousova, E., Armour, C., BosnicAnticevich, S., Thien, F., \& Jenkins, C., (2006): Double blind randomized controlled trial of two different breathing techniques in the management of asthma. Thorax, 61(8), 651-656. Available at: http://thorax.bmj.com/cgi/content/full /61/8/651. Accessed on 12 December 2013. 